\title{
Tributación medioambiental en Colombia. Otros impuestos al consumo: carbono, bolsas plásticas, gasolina y ACPM*
}

\section{Environmental Taxation in Colombia. Other Taxes on Consumption: Carbon, Plastic bags, Gasoline and ACPM}

\author{
CÉSAR J. SÁnchez MuÑoz ${ }^{1}$
}

\section{Sumario}

I. Introducción. II. Impuestos con fines medioambientales. A. Impuesto al carbono. 1. Estructura del hecho generador. a. Elemento objetivo. i. Aspecto material. ii. Aspecto temporal. iii. Aspecto cuantitativo. b. Elemento subjetivo. i. Sujeto activo. ii. Sujeto pasivo. B. Impuesto a las bolsas plásticas. 1. Estructura del hecho generador. a. Elemento objetivo. i. Aspecto material. ii. Aspecto temporal. iii. Aspecto cuantitativo. $b$. Elemento subjetivo.i. Sujeto activo. ii. Sujeto pasivo. III. Tributos que gravan los combustibles. A. Impuesto nacional a la gasolina y al ACPM. 1. Estructura del hecho generador. a. Elemento objetivo. i. Aspecto material. ii. Aspecto temporal. iii. Aspecto territorial. iv. Aspecto cuantitativo. b. Elemento subjetivo. i. Sujeto activo. ii. Sujeto pasivo. B. Contribución parafiscal al combustible. 1. Estructura del hecho generador. a. Elemento objetivo. i. Aspecto material. ii. Aspecto temporal. iii. Aspecto espacial y cuantitativo. b. Elemento subjetivo. i. Sujeto activo y pasivo. IV. Conclusiones. Bibliografía.

\section{Resumen}

El artículo da cuenta de la relación de exacciones en el ordenamiento jurídico colombiano con fines extrafiscales que, en Estudios Políticos de la Universidad Nacional de Colombia; Magíster en Investigación Interdisciplinario de la UD Francisco José de Caldas; Exconsultor Corte Constitucional; Consultor privado.

Docente investigador del CEEF.Correo-e: Cesar.sanchez@uexternado.edu.co 
teóricamente, buscan la protección del medioambiente, aunque en algunos casos su origen tiene un fin recaudatorio, en la medida en que la estructura del hecho generador no estaría configurado para buscar que los sujetos pasivos del gravamen redireccionaran su conducta.

Palabras clave: Extrafiscalidad, Medioambiente, Impuestos al consumo.

\begin{abstract}
The article gives an account of the relation of exactions in the Colombian legal system for extra-fiscal purposes that, theoretically, seek the protection of the environment, although in some cases its origin has a collection purpose, to the extent that the structure of the generating fact would not be configured to look for taxpayers to re-target their conduct.
\end{abstract}

Keywords: Extrafiscality, Environment, Taxes on consumption.

\section{Introducción}

Colombia es un Estado Constitucional de Derecho cuya estructura jurídica e institucional estaría diseñada para garantizar el bienestar de la sociedad, lo cual está en el contenido de la Carta Política y, en especial, en su preámbulo y en su artículo 2, los cuales desarrollan los fines del Estado. En este contexto, encontramos que la Constitución establece principios así como valores, y estos últimos, a pesar de su "carácter programático... su enunciación no debe ser entendida como un agregado simbólico, o como la manifestación de un deseo o de un querer sin incidencia normativa, sino como un conjunto de propósitos a través de los cuales se deben mirar las relaciones entre los gobernantes y los gobernados, para que, dentro de las limitaciones propias de una sociedad en proceso de consolidación, irradien todo el tramado institucional" (T-406/1996).

En este orden de ideas, en el diseño de las políticas públicas, el Estado tiene la posibilidad de emplear distintos mecanismos constitucionales y legales para lograr garantizar los derechos de los asociados. Y justamente uno de estos instrumentos de rango superior puede ser el tributo, que tiene dos funciones: por un lado, recaudar los recursos necesarios para solventar los gastos de la administración y, por el otro, desde la teórica económica, modificar conductas.

La Corte Constitucional, mediante Sentencia C-397/2011, determinó que a partir del artículo 95-9, que consagra los principios de solidaridad y generalidad, se entiende el deber de aportar a la construcción y desarrollo del proyecto de nación, lo cual también se relaciona con "el principio de reciprocidad que rige las relaciones de los ciudadanos con el Estado y entre éstos y la sociedad, a fin de equilibrar las cargas públicas que estructuran y sostienen la organización jurídico-política de la cual hacen parte, para armonizar y darle efectividad al Estado Social de Derecho".

Pero si por un lado la administración tiene la prerrogativa de exigir a las personas coadyuvar al éxito de las políticas públicas con el pago de exacciones, por el otro, la misma Constitución determina que en el marco de los fines del Estado las autoridades están en la obligación de garantizar los derechos de los ciudadanos. (C-826-13) (C- 
587/1992). Así las cosas, podemos encontrar que es plausible que el Estado, por medio de la imposición, intente modificar las conductas de los contribuyentes con fines constitucionalmente válidos, como es la protección medioambiental y, al mismo tiempo, recaudar ingresos para el fisco, lo que se conoce como la teoría del doble beneficio, es decir, la extrafiscalidad (Sánchez C., 2014).

Ahora bien, el presente escrito busca dar cuenta de las regulaciones del género de los impuestos al consumo que, en términos teóricos, buscarían salvaguardar el medioambiente (impuestos al carbono y las bolsas plásticas; gravámenes a los combustibles), pero que al final son más bien figuras recaudatorias que de todas formas tienen un fin extrafiscal, necesariamente, desde el punto de vista económico, pues provocan un impacto en el bolsillo del consumidor final, lo cual conlleva modificar conductas.

\section{Impuestos con fines medioambientales}

La protección medioambiental parte, en una primera instancia, de la utilización de medidas administrativas y punitivas, al evaluar la efectividad de estas políticas desde el punto de vista del costo-beneficio. Los estudios (OCDE) revelaron que se invierten más recursos a través de los mecanismos de regulación directa por parte del Estado, que con los instrumentos de autorregulación, como son los instrumentos impositivos que deberían incidir en un cambio de comportamiento por parte de los agentes de producción, considerando que racionalmente los agentes económicos buscarían optimizar sus utilidades, tributando menos con cargo a la renovación tecnológica o a la adecua- ción de conductas menos depredadoras del medioambiente.

En términos teóricos, emplear los tributos es plausible pero, dado que esto supone un sacrificio fiscal, se debe evaluar la eficiencia de estos instrumentos en el logro de los propósitos definidos, además de defender la estructura de los mismos e identificar los mecanismos más idóneos: el tipo de tributo (impuesto, tasa o contribución), así como los agentes, la base imponible, la tarifa y los mecanismos de control en la gestión (Varona, 2009).

Así, las exacciones constituyen instrumentos para lograr un punto de equilibrio entre la actividad económica y los distintos mecanismos de control que buscan mitigar el daño ambiental, prevenirlo y recuperar el ecosistema. En este sentido, se han ido desarrollando, además de los impuestos, una combinación de figuras: permisos de contaminación, command control y gasto fiscal (tax expenditure).

Por este camino se fue nutriendo el diseño de las políticas de protección medioambiental en Europa. En la década de los 70, la OCDE consolida el principio de contaminador pagador: quien afecta al medioambiente debe tener presente, desde el punto de vista económico, que debe asumir los costos de la afectación al ecosistema, es decir, sufragar los gastos de recuperar o desarrollar instrumentos para prevenir las afectaciones de contenido patrimonial (Herrera, 2000).

\section{A. Impuesto al carbono}

La quema de combustibles fósiles genera emisiones de dióxido de carbono, es decir, 
contaminación, que conlleva afectaciones a la salud de los seres vivos y a la producción de alimentos. Este fenómeno es conocido por los gobernantes desde hace más de 100 años; sin embargo, la valoración del problema estaba en los últimos puestos del listado de prioridades de las agendas gubernamentales.

Ahora bien, el panorama empieza a cambiar a mediados del siglo XX, cuando se presentó uno de los eventos más traumáticos de la historia reciente en relación con fenómenos medioambientales: "la gran niebla". En 1952, Londres fue cubierta por una bruma de contaminación como consecuencia de la quema de carbón, lo cual produjo la muerte de más de un millar de personas, pero que también dio lugar a que la administración de Churchill tomara medidas para controlar las emisiones. Décadas más tarde, la comunidad internacional buscó controlar el nivel de emisiones, no solo por los problemas de afectación a la salud humana, sino también por las consecuencias nefastas del fenómeno del calentamiento global producto de los gases de efecto invernadero.

En este contexto, se desarrolló el impuesto al carbono, como un instrumento de contenido económico para lograr que los individuos que queman combustibles fósiles modifiquen sus comportamientos para reducir las emisiones de $\mathrm{CO}_{2}$ o que sustituyan sus fuentes de energía por aquellas que no producen contaminación. Así, nace el impuesto al carbono, que no es otra cosa que un pago que realiza un individuo al Estado por las emisiones de dióxido de carbono a la atmósfera. En Colombia, dicho gravamen se incorpora a la legislación por medio de la Ley 1819 de 2016 como consecuencia, según el gobierno nacional, de cumplir con los compromisos adquiridos en la cumbre de París de 2015. De acuerdo con lo anterior, corresponde analizar cada uno los elementos de este tributo a partir de la teoría del hecho generador.

\section{i. Estructura del hecho generador}

\section{a. Elemento objetivo}

\section{i. Aspecto material}

El impuesto al carbono, desde el punto de vista teórico, se enmarca en el género de las exacciones al consumo, en la medida que esta categoría impositiva conlleva que el adquirente final interiorice el tributo vía precio, fenómeno conocido como "impuestos a las ventas de etapa única" (Villegas, 2009). Así, se entendería que la imposición en cuestión grava el consumo de los combustibles fósiles destinados a la quema para la producción de energía.

En efecto, el Artículo 221 de la Ley 1819 de 2016 determina como materia imponible el "contenido de carbono de todos los combustibles fósiles" y su causación se genera en una sola de las etapas del proceso de comercialización. La legislación colombiana estableció la primera fase del ciclo comercial como hecho imponible, es decir, la venta en el territorio nacional, entrega del distribuidor o importación, cualquiera de ellas que ocurra primero.

En este contexto, encontramos que, por ejemplo, el ingreso a territorio nacional de los combustibles fósiles per se no da nacimiento a la exacción, pues deben estar destinados a la combustión para generar energía, lo cual es avalado por la administración tributaria al referirse específicamente a una 
consulta sobre la adquisición de gas licuado y natural.

Como se observa el impuesto a carbono, en su finalidad busca gravar la adquisición de combustibles fósiles, siempre y cuando el mismo [sic] sean utilizados con fines energéticos, y generen combustión de acuerdo con lo previsto en el hecho generador, NO es sólo su simple adquisición, ya que se requiere que la misma cumpla los anteriores supuestos (DIAN, 2017).

Ahora bien, es importante tener en cuenta que en las hipótesis de ventas en el territorio nacional se encuentra la pregunta de cuándo se perfecciona dicho negocio jurídico, lo cual se daría con el acuerdo entre cosa y precio (elementos esenciales). Sin embargo, esto generaría una suerte de pago anticipado del combustible y, por supuesto, de la exacción en la medida que las solicitudes al distribuidor (Ecopetrol) se realizan con varios meses de antelación, dando lugar a problemas de flujo de caja, pues el combustible se despacha tiempo después de la solicitud, dependiendo de la disponibilidad del producto.

En relación con el escenario del retiro del combustible, encontramos que habría que precisar que si es al momento de despachar el recurso o al de recibirlo, pues en los casos de poliductos y oleoductos pueden llegar a pasar varios días para que el comprador que usará el combustible como fuente energética lo reciba.

\section{- Supuestos de no sujeción y exclusión}

La reforma tributaria de 2016 establece varias situaciones en las cuales, a pesar de que el hecho imponible se realiza, no nace la obligación tributaria. En este sentido, encontramos "el uso de estos derivados del petróleo cuando los mismos son utilizados para la prestación de servicios públicos domiciliarios" (DIAN, 2017).

Así mismo, quienes demuestren remociones o reducciones de gases de efecto invernadero y obtengan el certificado carbono neutro (Art. 221, parágrafo 3) estarán excluidos del gravamen. Dicho certificado es dado por una empresa avalada por las autoridades colombianas, que debe dar fe de que existen de forma concreta los requisitos planteados. La regulación sobre la materia está dada por medio del decreto reglamentario expedido por el Ministerio de Hacienda con la colaboración con el Ministerio de Ambiente y Desarrollo sostenible. Esta regulación fue incorporada mediante el decreto 926 del 1 de junio de 2017.

Los combustibles destinados a la exportación también se encuentran excluidos del tributo (Art. 221, parágrafo 5). Esta disposición sirvió como base para evitar que los reaprovisionamientos de aeronaves de vuelos internacionales y de buques terminara siendo objeto de la exacción. Según el artículo 110 del Decreto 2385 de 1999, "“[a] los buques o aeronaves en tráfico internacional que salgan con destino final al extranjero se les autorizará embarcar las provisiones para llevar y las provisiones para consumo necesarias para el funcionamiento y conservación del medio de transporte. El reaprovisionamiento de los buques o aeronaves que lleguen al territorio aduanero nacional se considerará una exportación”. Finalmente, "el alcohol carburante y el biocombustible de origen vegetal, animal o producido a partir de residuos sólidos urbanos de producción nacional con 
destino a la mezcla con ACPM para uso en motores diésel, no están sujetos al impuesto al carbono".

\section{ii. Aspecto temporal}

En primera instancia, es necesario precisar que no existe una concordancia entre la materia imponible, esto es, emplear combustibles fósiles con fines energéticos "siempre que sean usados para combustión", y la causación del tributo, lo cual no es extraño, pues esto sucede en la gran mayoría de los impuestos al consumo (Gianni, 1957). De todas formas, al tratarse de un tributo de carácter monofásico, su causación se da con la entrega, facturación e importación de los combustibles fósiles.

La obligación tributaria en cuestión se realiza en el territorio nacional; sin embargo, existen situaciones especiales, las cuales serían las zonas francas y los 12 departamentos considerados como área de frontera (Resolución 41282 del 20 de diciembre de 2016 del Ministerio de Minas).

\section{iii. Aspecto cuantitativo}

La base imponible del tributo (Art. 222) estaría acorde con el factor de emisión de dióxido de carbono a una tarifa de 15 mil pesos por tonelada de $\mathrm{CO}_{2}$. Sin embargo, en la exposición de motivos de la Ley 1819, no se especifica o determinan los criterios que dan lugar a dicho monto. En relación con la tarifa corresponde la siguiente tabla, y el monto de esta se ajustará cada primero de febrero, de acuerdo con la inflación más un punto, y la tarifa se estabilizará hasta llegar a una UVT. Lo que no queda claro es qué pasa después de que llegue a dicho valor.

\begin{tabular}{|c|c|c|}
\hline Combustible fósil & Unidad & Tarifa/unidad COP \\
\hline Gas natural & Metro cúbico & $\$ 29$ \\
\hline Gas licuado de petróleo & Galón & $\$ 95$ \\
\hline Gasolina & Galón & $\$ 135$ \\
\hline Kerosene y jet fuel & Galón & $\$ 148$ \\
\hline ACPM & Galón & $\$ 152$ \\
\hline Fuel oil & Galón & $\$ 177$ \\
\hline
\end{tabular}

Como se puede observar, no se incluye el carbón dentro del sistema tarifario, lo cual llama la atención en la medida que la materia imponible recae sobre todos los combustibles fósiles que sean quemados como fuente energética. En relación con los plazos para declarar y pagar el impuesto, el DUT (Art. 1.6.1.13.2.54.) establece que estos serán bimestrales, así: enero-febrero; marzoabril; mayo-junio; julio agosto; septiembreoctubre, y noviembre-diciembre. Así mismo, cada año, la autoridad tributaria definirá las fechas específicas de pago y presentación.

\section{b. Elemento subjetivo}

\section{i. Sujeto activo}

La legislación (Art. 222) establece que será la Dirección de Impuestos y Aduanas $\mathrm{Na}$ cionales la entidad encargada de realizar el cobro del gravamen y adelantar los procesos 
de investigación, determinación, discusión y cobro, de acuerdo con los parámetros establecidos en el Estatuto Tributario. En este sentido, la entidad mediante acto administrativo establece los formularios y demás regulaciones para el pago de la exacción.

Ahora bien, los recursos recaudados por esta imposición tendrán destinación específica a través del Ministerio de Hacienda, esto es, para financiar la Sostenibilidad Ambiental y Desarrollo Rural Sostenible en Zonas Afectadas por el Conflicto ("Fondo para una Colombia Sostenible") de que trata el artículo 116 de la Ley 1769 de 2015 (presupuesto general de la nación). Al final, los dineros servirían para contratar proyectos definidos por la cartera de ambiente y generar trabajo en la conservación de las cuencas, controlar la erosión, etc. Finalmente si el contribuyente no cancela la obligación "en la forma señalada en el reglamento que expida el Gobierno nacional", se entiende como no presentada la declaración y habría un reenvido al Estatuto Tributario.

\section{ii. Sujeto pasivo}

La definición del sujeto pasivo fue incluida por el legislador en el desarrollo del aspecto material del tributo (Art. 221), pues este establece que quien adquiera el combustible para quemarlo como fuente energética tendrá que cancelar la exacción. Así, el artículo 221 señala al "productor o el importador; el productor cuando realice retiros para consumo propio; y el importador cuando realice retiros para consumo propio".

Finalmente, son responsables del impuesto, tratándose de derivados de petróleo, los productores y los importadores; independientemente de su calidad de sujeto pasivo, cuando se realice el hecho generador. La DIAN, mediante concepto 05314 del 14 de marzo de 2017, explica que al final existe un sujeto pasivo económico, el consumidor final, quien termina asumiendo el costo del gravamen y que este valor será deducible del impuesto sobre la renta de acuerdo con el artículo 107 del ET para quienes cumplen los requisitos de dicha disposición.

\section{B. Impuesto a las bolsas plásticas}

El plástico es un producto derivado del petróleo que se usa en la vida diaria en todas las partes del mundo, el cual es económico y versátil para envolver cualquier producto y poder conservarlo o transportarlo. Sin embargo, es altamente nocivo para el medioambiente, pues puede llegar a tardar hasta un siglo en biodegradarse, lo cual ha generado en las últimas décadas preocupación en algunos gobernantes de distintos países que buscan crear incentivos para disminuir su uso.

En el caso de Colombia, es paradójico, pues el diseño de la figura es precario y al final serán las grandes superficies las más beneficiadas porque dejarán de invertir recursos en las bolsas y trasladarán el costo a los compradores. Tampoco quedó de forma expresa el tema sancionatorio frente al incumplimiento de esta obligación tributaria.

\section{Estructura del hecho generador}

\section{a. Elemento objetivo}

\section{i. Aspecto material}

El tributo que se incorpora en el ET en el Artículo 512-1 grava la "entrega", en un establecimiento de comercio, ya sea a título 
oneroso o gratuito, de las bolsas que no sean reutilizables para cargar o llevar productos. La Ley dejó por fuera de la exacción los siguientes empaques:

1. Aquellas cuya finalidad no sea cargar o llevar productos adquiridos en el establecimiento que la entrega.

2. Las que sean utilizadas como material de empaque de los productos pre-empacados.

3. Las biodegradables certificadas como tal por el Ministerio de Ambiente y Desarrollo Sostenible, con base en la reglamentación que establezca el Gobierno nacional.

4. Las bolsas reutilizables que conforme a la reglamentación del Gobierno nacional posean unas características técnicas y mecánicas que permiten ser usadas varias veces, sin que para ello requieran procesos de transformación.

\section{ii. Aspecto temporal y espacial}

La causación del gravamen concuerda con la realización del hecho imponible, es decir, la "entrega" del bien, y además en la factura y/o documento equivalente debe detallarse el número de bolsas y el valor del gravamen. En relación con el aspecto territorial, la obligación tributaria se realiza en el espacio geográfico colombiano y no se distinguen tratamientos diferenciados para zonas de frontera.

\section{iii. Aspecto cuantitativo}

A partir de la entrada en vigencia de este gravamen el 1 de julio de 2017, se cobran las siguientes tarifas, las cuales se actualizarán al 30 de noviembre de cada año y antes del primero de enero la DIAN publicará las mismas actualizadas.

\begin{tabular}{|c|c|}
\hline Año & Tarifa en pesos por bolsa \\
\hline 2017 & $\$ 20$ \\
\hline 2018 & $\$ 30$ \\
\hline 2019 & $\$ 40$ \\
\hline 2020 & $\$ 50$ \\
\hline
\end{tabular}

Fuente: Ley 1819 de 2016.

Ahora bien, la "tarifa de las bolsas plásticas que ofrezcan soluciones ambientales será del $0 \%, 25 \%, 50 \%$ o $75 \%$ del valor pleno de la tarifa, según el nivel (de 1 a 4) de impacto al medioambiente y la salud pública, definido por el Ministerio de Ambiente y Desarrollo Sostenible". Finalmente, esta exacción no podrá llevarse como un costo o gasto y tiene un problema en los montos pagados porque en circulación la moneda de menor cuantía es de 50 pesos y cómo hacer efectivo el cambio.

\section{b. Elemento subjetivo}

\section{i. Sujeto activo}

La Ley no definió el sujeto activo de la obligación tributaria y tampoco estableció cuáles son las sanciones que se podrán imponer en el caso de incumplimiento de la obligación tributaria. Sin embargo, vía reglamento, el gobierno saneará la situación y la DIAN tendrá la responsabilidad, máxime que en las facturas o documento equivalente 
se relaciona el cobro del impuesto y dicha entidad certificará las tarifas.

\section{ii. Sujeto pasivo}

En primera instancia, quien asume la carga del pago de la exacción es quien recibe la bolsa, y son responsables del tributo quienes entregan la bolsa y pertenecen al régimen común de IVA. Ahora bien, más allá del hecho generador, la configuración del tributo en términos prácticos deja por fuera a comerciantes informales y a un gran número de personas del régimen simplificado. Finalmente, la ley da la oportunidad a los comerciantes que se acojan al monotributo de que el costo del gravamen a las bolsas plásticas forme parte de la tarifa de aquel.

En la exposición de motivos de la hoy Ley 1819 de 2016, se estableció de manera expresa que se buscaba acabar con "la distribución gratuita de bolsas plásticas en los puntos de pago de los almacenes, supermercados y tiendas de cadena". Esta regulación genera una controversia, pues por un lado están quienes afirman que es un beneficio para dichas sociedades, que pueden llevar como costo o gasto los dineros invertidos en la compra de dichos bienes, lo cual al final no sería novedoso. Por el otro lado, en relación con el IVA, el tributo continúa vigente y de todas formas existe el problema de cómo resolver el tema y las soluciones que el sector utiliza.

\section{Tributos que gravan los combustibles}

\section{A. Impuesto nacional a la gasolina y al ACPM}

El uso de automotores y en general los motores a combustión generan externalida- des negativas para el medioambiente como consecuencia, principalmente, de las emisiones de dióxido de carbono a la atmósfera, lo cual impacta la salud, no solo de la especie humana, sino de toda la vida del planeta, por lo cual se buscaría disminuir el uso de las fuentes energéticas de carácter fósil.

Una de las formas de lograr el fin en cuestión es incrementando el precio del petróleo y sus derivados al imponer tributos y apelar a una función extrafiscal. Sin embargo, en la realidad, lo que llevó a gravar los combustibles fue la necesidad de recaudo por parte del Estado. Así, por ejemplo, en Chile, este gravamen se establece para financiar la reconstrucción del país después del terremoto de 1985, en Europa se establece a principios de la década de los 90 y así en el resto del mundo. De todas formas, es innegable que, al final, esta exacción sí tiene un impacto en el cambio del comportamiento de los consumidores y por supuesto de los fabricantes de vehículos que buscan que dichos artefactos sean más eficientes.

En Colombia, la imposición a la gasolina y el ACPM se encontraba en los artículos 83 y siguientes de la Ley 14 de 1983; luego, en los artículos 45 y 46 de la Ley 6 de 1992; posteriormente, en la Ley 223 de 1997, en sus artículos 58 y 59, así como en el Estatuto tributario, los cuales fueron modificados por la Ley 1607 de 2012 en su artículo 167, dando lugar a una sola regulación en relación con el gravamen sobre los combustibles en el contexto de los tributos al consumo. Con la entrada en vigencia de la Ley 1819 de 2016 (Art. 218), se cambian las disposiciones que estuvieron vigentes por cerca de cuatro años. 


\section{Estructura del hecho generador}

\section{a. Elemento objetivo}

\section{i. Aspecto material}

El hecho imponible se mantiene en términos generales (Art. 218 de la Ley 1819/2016); así, la obligación tributaria nace como consecuencia de la "venta, retiro, importación para el consumo propio o importación para la venta de gasolina y ACPM". El parágrafo 1 de este artículo define lo que se entiende por ACPM: "el aceite combustible para motor, el diésel marino o fluvial, el marine diésel, el gas oil, intersol, diésel número 2 , electro combustible o cualquier destilado medio $\mathrm{y} / \mathrm{o}$ aceites vinculantes, que por sus propiedades físico químicas al igual que por sus desempeños en motores de altas revoluciones, puedan ser usados como combustible automotor".

En relación con la gasolina, encontramos que esta es corriente y extra, "la nafta o cualquier otro combustible o líquido derivado del petróleo que se pueda utilizar como carburante en motores de combustión interna diseñados para ser utilizados con gasolina". Esta definición nos lleva a entender que los aditivos para los combustibles también se encuentran gravados.

Ahora bien, como se deduce de la disposición, son tanto los productores como los importadores quienes cobran y recaudan el gravamen de "tal manera, que en las ventas posteriores efectuadas por los distribuidores a los consumidores finales no se causa el tributo, en virtud de lo cual, los últimos no son sujetos pasivos del mismo, y por ende no pagan el impuesto, sino que el mismo hace parte del costo desde el momento en que se canceló en la importación o en la primera venta efectuada por el productor" (DIAN, 2008).

Finalmente, existe un asunto sin resolver que se refiere a los inventarios que fueron adquiridos antes de entrada en vigencia de la reforma tributaria, lo cual no solo impacta este gravamen, sino el IVA. La ACP los calcula en cerca de 90 mil millones de pesos.

- Supuestos de no sujeción y exenciones

Teniendo en cuenta que existen regiones del país que no se encuentran conectadas a la red nacional de electricidad y que para poder tener acceso a la energía convencional deben autogenerar con plantas que funcionan con combustibles fósiles, el legislador exceptuó del gravamen dichas "zonas no interconectadas".

Además de lo anterior, el parágrafo primero de la disposición en cuestión también deja por fuera del gravamen las mezclas del tipo IFO utilizadas para el funcionamiento de grandes naves marítimas y turbo combustible de aviación. En este último grupo, encontramos el JET A1 para aviones comerciales que es similar al keroseno o ACPM; y también el JP4 que utilizan los equipos militares, esto es helicóptero y demás aviones (de carga y combate). En general es utilizado para aeronaves y equipos de turbina, pues tiene mayor octanaje, además de que el punto de inflamación es superior a los 38 grados Celsius. Finalmente, el texto legal excluye las "gasolinas del tipo 100/130", usadas por los aviones de pistón que en general cubren las zonas mas apartadas del país. En principio, la justificación de no gravar estos combustibles sería evitar el encarecimiento del costo del transporte. 
Por otra parte, las exportaciones en la legislación colombiana en principio no están gravadas y ello da cuenta de por qué "la venta de diésel marino y combustibles utilizados para reaprovisionamiento de los buques en tráfico internacional" no da lugar al pago de la exacción (Parágrafo 2) y explica además el derecho de los distribuidores mayoristas, comercializadores, etc., al reintegro del tributo pagado siempre y cuando acrediten que se trató de una negociación en los términos mencionados.

\section{ii. Aspecto temporal}

Este gravamen es de carácter instantáneo, por lo cual la obligación tributaria nace al momento de realizarse al darse cualquiera de las varias hipótesis que consagra la disposición, eso sí la primera que se presente. Así, la exacción tiene lugar al momento de la venta por parte del productor; o a la emisión de la factura; o al retiro para consumo del productor y finalmente en la fecha en que se realice la nacionalización de la gasolina o el ACPM.

\section{iii. Aspecto territorial}

El territorio aduanero nacional es el lugar en donde se realiza el hecho generador; sin embargo, la legislación establece, a propósito de este aspecto del elemento objetivo de la relación jurídico tributaria, tratamientos diferenciados, pues en algunos casos se trata de exportaciones que se realizan en zonas francas o portuarias o porque se buscan fines extrafiscales, como la protección de la economía de una región.

Así, el Artículo 173 de la reforma tributaria de 2016 modificó el primer inciso del Artículo $9^{\circ}$ de la Ley 1430 de 2010 para determinar que en los departamentos y municipios en zonas de frontera se presenta la exclusión de IVA, y la exención de aranceles e impuesto nacional a la gasolina y al ACPM. Para llevar a cabo el cumplimiento de este mandato legal, es el Ministerio de Minas y Energía el que distribuye los combustibles líquidos en dichas regiones y define los parámetros de comercialización y demás detalles (Min. Minas y Energía, Resolución No 40266 del 31-03-2017).

\section{iv. Aspecto cuantitativo}

La base gravable del impuesto en cuestión se ajustará cada 1 de febrero a partir del año 2018, y el monto a pagar se determinará de la siguiente manera:

\begin{tabular}{|c|c|c|}
\hline \multicolumn{3}{|c|}{ BASE DEL IMPUESTO NACIONAL A LOS COMBUSTIBLES } \\
\hline$\#$ & Combustible & Valor por galón - COP \\
\hline 1 & Gasolina corriente & 490 \\
\hline 2 & Gasolina extra & 930 \\
\hline 3 & ACPM & 469 \\
\hline 4 & Combustibles que la ley define como gasolina/ ACPM & 490 \\
\hline
\end{tabular}

Elaboración propia 
El legislador, consciente del impacto en el costo de la gasolina y el ACPM por cuenta del gravamen en cuestión, determinó que del presupuesto general de la nación se podían destinar recursos para el Fondo de Estabilización de Precios de Combustible (FEPC).Así mismo, la ley establece que el impuesto nacional a la gasolina y al ACPM puede ser deducible del impuesto sobre la renta, en los términos del artículo 107 del Estatuto Tributario, cuyas vicisitudes son aclaradas por la DIAN mediante Oficio $N^{\circ} 002334$ del 2 de febrero de 2017.

El tema de la deducibilidad de este gravamen es tratado por la jurisprudencia administrativa, pues de la "norma se infiere con claridad, que fue voluntad del legislador autorizar la deducibilidad de los impuestos que de manera expresa se señalan en la norma (sic); y que dos son los requisitos para que proceda su deducción, esto es, que se trate de aquellos efectivamente pagados durante el respectivo año gravable y que tengan relación de causalidad con la actividad productora de renta del contribuyente" (Sentencia, T.A.C. Exp. 250002327000201000065-01 del 2 de septiembre de 2011).

Así mismo, fue derogado (numeral 3 del Artículo 376 de la Ley 1819/2016) el beneficio consagrado en el Artículo 176 de la Ley 1607 de 2012, que establecía la posibilidad para los responsables del IVA de deducir el impuesto nacional a la gasolina y al ACPM pagado por el contribuyente, aunque la DIAN, mediante Oficio $N^{\circ} 002334$ del 2 de febrero de 2017, explica el procedimiento para descontar el beneficio del 35\% partiendo del Decreto 3037 del 2013, lo cual creemos que es un error pues dicho decreto decayó al derogarse la disposición de la reforma de 2012 mencionada (C-069 /1995).

\section{b. Elemento subjetivo}

\section{i. Sujeto activo}

La Ley 1819 de 2016 modificó parcialmente la reforma tributaria de 2012 en lo que se refiere el tributo en cuestión, de tal forma que mantuvo intacta la disposición que define el sujeto activo de la exacción objeto de estudio. Así, el Artículo 169 establece que administración y recaudo corresponden a la Dirección de Impuestos y Aduanas Nacionales, "para lo cual tendrá las facultades consagradas en el Estatuto Tributario para la investigación, determinación, control, discusión, devolución y cobro de los impuestos de su competencia, y para la aplicación de las sanciones contempladas en el mismo y que sean compatibles con la naturaleza del impuesto". En este orden de ideas, este texto legal se vincula al Decreto 4048 de 2008 relativo a la competencia funcional de esta entidad en lo relativo al Impuesto Nacional a la Gasolina y al ACPM .

Así, mediante Resolución No 00000401 02-2017, la DIAN reguló las tarifas de esta en San Andrés, Providencia y Santa Catalina; y con Resolución No 000006 del 03-02-2017 prescribió y habilitó los formularios para el cumplimiento de las obligaciones tributarias en el año 2017.

\section{ii. Sujeto pasivo}

La obligación tributaria recae sobre quien adquiera "la gasolina o el ACPM del productor o el importador; el productor cuando realice retiros para consumo propio; y el importador cuando, previa nacionalización, realice retiros para consumo propio". Así mismo, "son responsables del impuesto el 
productor o el importador de los bienes sometidos al impuesto, independientemente de su calidad de sujeto pasivo, cuando se realice el hecho generador".

Es importante tener presente que el Art. 61 de la Ley 812 de 2003 define los agentes de la cadena de distribución de los combustibles que comienza con el refinador y termina con el distribuidor minorista y el gran consumidor. Ahora bien, más allá de la regulación, al final el pago termina soportándolo vía precio es el consumidor final, quien en la mayoría de los casos no podrá beneficiarse de la deducción vía renta, pues solo un grupo reducido de contribuyentes podrá demostrar que sus ingresos tienen relación de causalidad directa con la cancelación de la exacción.

\section{B. Contribución parafiscal al combustible}

En 2007, el Congreso aprobó el Plan Nacional de Desarrollo (PND), que en su Artículo 69 creó el Fondo de Estabilización de Precios de los Combustibles, reglamentado por el Decreto 4839 de 2008. Una entidad sin personería jurídica, dependiente del Ministerio de Hacienda y Crédito Público con el propósito de evitar que las fluctuaciones de los precios internacionales afecten el costo de los combustibles en el mercado doméstico y cuyos fondos en principio provenían de Ecopetrol. Posteriormente, la Ley 1450 de 2011 mantuvo en términos generales la estructura y financiamiento de dicho ente, pero adicionó una fuente de financiamiento que fue declarada inexequible por la Corte Constitucional, pues este ingreso a juicio de la Corporación era "un recaudo de naturaleza tributaria" (C-621/2013).
En efecto, el Artículo 101, literal C, del PND estableció que "los recursos provenientes de las diferencias negativas, entre el precio de paridad internacional y el precio de referencia establecido por el Ministerio de Minas y Energía, o quien haga sus veces, cuando existan" se destinarían al Fondo. Para la Corte Constitucional, esta regulación constituye un tributo, de acuerdo con las siguientes consideraciones:

El recaudo previsto por el literal acusado deba ser considerado dentro del género de los tributos, se funda en que dicho sistema de obtención de los recursos por parte del FEPC corresponde a un ingreso de carácter parafiscal, en cuanto el mismo cumple con los elementos que la jurisprudencia de esta Corte y el artículo 29 del Estatuto Tributario asignan a estos recursos:

Los recursos recaudados dependen del precio de referencia establecido por el Ministerio de Minas y Energía, con base en reglas fijadas por el mismo Ministerio, es decir, son consecuencia de una política pública de recaudo con el objetivo de nutrir de recursos al FEPC. En este sentido, resultan consecuencia del poder coercitivo del Estado... Es obligatorio, pues ni refinadores ni importadores, como supuestos sujetos pasivos de la contribución, pueden sustraerse de consignar en las cuentas del Fondo el diferencial de participación que trimestralmente determine, por medio de Resolución, el Ministerio de Minas y Energía;

El diferencial de participación afectaría a un grupo específico: importadores de combustibles y productores de combustibles en el territorio nacional. Los recursos recaudados 
por esta vía por el FEPC tienen naturaleza pública, es decir, son recursos públicos;

Los recursos por esta vía recaudados serán utilizados para pagar el diferencial de compensación, es decir, serán los dineros que emplee el Fondo para compensar a los importadores y refinadores nacionales cuando el precio al que deban vender el combustible sea inferior al precio de paridad internacional -artículos $1^{\circ}, 6^{\circ}$ y $7^{\circ}$ del decreto 2713 de 2012-. Estos recursos tienen como único objetivo atenuar en el mercado interno las consecuencias negativas de las fluctuaciones en el precio de paridad internacional de los combustibles -artículo $2^{\circ}$ del decreto 2713 de 2012-, lo que implica un beneficio directo para importadores y refinadores, es decir, el sector económico de donde en la práctica se recaudan los recursos;

Los recursos por esta vía recaudados, así como el resto de recursos del Fondo, no hacen parte del presupuesto nacional, sino que se consignan en la cuenta del FEPC -parágrafo del artículo 101 de la ley 1450 de 2011-; y finalmente, los recursos del Fondo son administrados por el Ministerio de Hacienda y Crédito Público.

Adicionalmente a estos elementos específicos, una interpretación integral y sistemática del mecanismo de financiación del FEPC creado por el literal C) del artículo 101 de la ley 1450 de 2011 evidencia que:

a) En todo el sistema de estabilización de precios, subyace el principio de que el mismo va a funcionar, principalmente, con los recursos recaudados de un sector de la economía - éste corresponde a quienes impor- tan o quienes producen, y por tanto venden, combustibles en territorio colombiano-; y

b) El eventual recaudo se presenta cuando el precio de referencia excede del precio de paridad internacional y no es otra autoridad distinta al Ministerio de Minas y Energía la que tiene competencia para decidir cuándo ocurre esta eventualidad.

Así las cosas, es expulsada del ordenamiento jurídico una figura para recaudar ingresos para el FEPC que daría lugar a que más adelante, en la Ley 1439 de 2014, se incorporara la primera versión oficial de la contribución parafiscal al combustible, pues la anterior, como se puede concluir, era un tributo "disfrazado". La exacción de la reforma tributaria en mención fue declarada inexequible por la Corte Constitucional mediante Sentencia C-726/2015, pero esta vez por vicios de procedimiento en el trámite legislativo.

Ahora bien, en 2015 la Comisión de expertos para una reforma estructural en materia tributaria recomendó revivir esta exacción, pues "la creación de la contribución parafiscal al combustible permitirá contar de nuevo con este mecanismo de ahorro, que a su vez evitará que se genere una mayor deuda para el gobierno nacional (que a su vez implica un mayor servicio a la deuda y un mayor déficit fiscal", esto porque, como ya se mencionó, los recursos para el Fondo provenían de Ecopetrol y del presupuesto general de la nación. Así las cosas, la Ley 1819 de 2016 revivió el tributo, del cual corresponde dar cuenta. 


\section{Estructura del hecho generador}

\section{a. Elemento objetivo}

\section{i. Aspecto material}

La obligación tributaria nace cuando el refinador (productor) o importador vende (Art. 225 L. 1819/16) gasolina o ACPM al distribuidor mayorista de combustibles, de tal manera que esta exacción tiene por supuesto un carácter monofásico. Así mismo, en la hipótesis de que el importador tenga también la calidad de distribuidor mayorista, "el hecho generador será el retiro del producto destinado a la actividad mayorista". Así mismo, teniendo en cuenta que la regulación en cuestión no estableció un concepto de qué se entiende por gasolina y ACPM debemos apelar a las definiciones que se encuentran en el ordenamiento jurídico y específicamente en las mencionadas en el impuesto a los combustibles referenciado anteriormente.
De todas formas, en la cadena de agentes de distribución: 1. refinador, 2. transportador (tubo o camión), 3. distribuidor mayorista, 4 . transportador, 5. distribuidor minorista -estación de servicio, 6. consumidor final, será el colombiano de a pie quien nuevamente vía precio termine asumiendo el tributo.

- Supuestos de no sujeción y exenciones

En relación con las exenciones, la disposición dejó por fuera del gravamen al distribuidor mayorista que vende ACPM a los grandes consumidores individuales no intermediarios, así como las ventas entre refinadores, entre distribuidores mayoristas, entre importadores y entre refinadores e importadores. Asimismo, quedan excluidas las ventas del producto importado de países vecinos, autorizadas por el Ministerio de Minas y Energía, y cuyo precio es fijado por este para atender el abastecimiento de combustibles en zonas de frontera.

\begin{tabular}{|c|c|c|}
\hline \multicolumn{3}{|c|}{ EXENCIONES } \\
\hline Distribuidor mayorista & \multirow{5}{*}{ Venta a } & $\begin{array}{l}\text { Grandes consumidores individuales no interme- } \\
\text { diarios de ACPM }\end{array}$ \\
\hline Refinador & & Refinador \\
\hline Distribuidor mayorista & & Distribuidor mayorista \\
\hline Importador & & Refinador \\
\hline Refinador & & Importador \\
\hline Importaciones para zor & le fronter & cuyo precio define el Min.Minas \\
\hline
\end{tabular}

Elaboración propia.

\section{ii. Aspecto temporal}

El Artículo 227 establece que la exacción nace cuando, en el periodo gravable, la sumatoria de los diferenciales de participación sea mayor que la sumatoria de los diferenciales de compensación. Así mismo, una vez se genera la obligación tributaria, la misma se calculará "a través de la liquidación de la posición neta trimestral de cada refinador o importador con respecto al FEPC con base en el reporte de información que los refinadores y/o impor- 
tadores presenten. En caso de que la sumatoria de los diferenciales de participación sea mayor que la sumatoria de los diferenciales de compensación y se cause la contribución, el Ministerio de Minas y Energía ordenará al refinador o al importador el pago a favor del Tesoro Nacional dentro de los 30 días calendario siguientes a la ejecutoria del acto de liquidación" (Art. 231 L. 1819/16).

\section{iii. Aspecto espacial y cuantitativo}

La obligación tributaria se realiza en el territorio colombiano, teniendo en cuenta la producción nacional, que básicamente está en cabeza de Ecopetrol, y las importaciones de gasolina. Al final, no se plantea ninguna situación diferencial en zonas francas, pero sí un tratamiento diferenciado en las zonas de frontera.

En relación con el aspecto cuantitativo, encontramos que para calcular la base gravable (Art. 228 L. 1819/16) se parte de la diferencia que se presente entre el ingreso del productor y el "precio de paridad internacional, cuando el primero es mayor que el segundo en la fecha de emisión de la factura de venta, multiplicada por el volumen de combustible vendido". Así mismo, la tarifa corresponde al $100 \%$ de la base gravable (Art. 229 L. 1819/16). Finalmente, la ley define exactamente cada uno de los conceptos de la siguiente manera:

a) DIFERENCIAL DE COMPENSACIÓN. Es la diferencia presentada entre el Ingreso al Productor y el Precio de Paridad Internacional, cuando el segundo es mayor que el primero en la fecha de emisión de la factura de venta, multiplicada por el volumen de combustible vendido; b) DIFERENCIAL DE PARTICIPACIÓN. Es la diferencia presentada entre el Ingreso al Productor y el Precio de Paridad Internacional, cuando el primero es mayor que el segundo en la fecha de emisión de la factura de venta, multiplicada por el volumen de combustible vendido;

c) INGRESO AL PRODUCTOR. Es el precio por galón fijado por el Ministerio de Minas y Energía o por la entidad que haga sus veces, al que los refinadores e importadores venden la gasolina motor corriente o el ACPM, para atender el mercado nacional;

d) PRECIO DE PARIDAD INTERNACIONAL. Es el precio calculado por el Ministerio de Minas y Energía, de acuerdo con la metodología expedida para el efecto, tomando como referencia el precio diario de los combustibles en el mercado de la Costa Estadounidense del Golfo de México u otro mercado competitivo. Para el caso de las importaciones, se tendrán en cuenta los costos asociados para atender el abastecimiento nacional determinados por el Ministerio de Minas y Energía;

e) VOLUMEN DE COMBUSTIBLE. Es el volumen de gasolina motor corriente o de ACPM reportado por el refinador o el importador.

\section{b. Elemento subjetivo}

\section{i. Sujetos activo y pasivo}

El titular de los derechos económicos es la nación (Art. 223 L. 1819/16) a través del Ministerio de Hacienda y Crédito Público como administrador del Fondo de Estabilización de Precios de los Combustibles (FEPC). Sin embargo, es el Ministerio de Minas y Ener- 
gía el que "ejercerá las funciones de control, gestión, fiscalización, liquidación, determinación, discusión y cobro de la contribución, de acuerdo con las normas de procedimiento establecidas en el Estatuto Tributario" (Art. 231 L. 1819/16).

En este orden de ideas, la cartera en cuestión se encarga de los procesos de determinación de la contribución a "cargo de los refinadores o importadores que reporten información inexacta o no reporten la información para calcular y liquidar esa contribución dentro de los plazos definidos en el reglamento, y hará exigibles las cesiones liquidadas mediante procedimientos de cobro coactivo, de acuerdo con lo establecido por la Ley 1066 de 2006" (Art. 232 L. 1819/16), y además tendrán que pagar los intereses que sean del caso.

Finalmente, el sujeto pasivo y responsable de la contribución es el refinador o importador de gasolina motor corriente o ACPM que realice el hecho generador (Art. 226).

\section{Conclusiones}

El panorama de los tributos que gravan los combustibles en Colombia básicamente obedece más a una intención de recaudo que a fines extrafiscales de protección medioambiental, porque en la configuración de todos los gravámenes (carbono, bolsas, impuestos a los combustibles y parafiscales) no está diseñada para buscar un recaudo nulo, pues el éxito de una exacción verde es recaudar poco porque los contribuyentes cambiarán sus comportamientos y no pagarán la imposición, y esto significa no impactar el ecosistema.

Ahora bien, toda la carga impositiva a la gasolina y el ACPM, por supuesto, genera un impacto en el bolsillo de los consumidores finales, quienes al final buscarán minimizar el costo, dejando de consumir dichos recursos energéticos, pero esto es por una situación de elección racional del consumidor.

En relación con la contribución parafiscal a los combustibles, la figura es necesaria para estabilizar los precios a los combustibles en el mercado doméstico, pues los precios internacionales fluctúan y esto conlleva aumentos o decrecimientos en el costo de la gasolina y ACPM, lo cual genera que el Estado deba financiar el gasto de estabilización, lo cual es bastante costoso, incluso el déficit es de 5,4 billones de pesos, según la Contraloría General de la República. 


\section{Bibliografía}

Amador Cabra, L. E. (2014). “Análisis Económico del Derecho: un paradigma en construcción”, en D.d. Económico, Serie de derecho económico. Análisis económico del derecho. Nuevas vertientes y diferentes aplicaciones (Vol. 3, págs. 13-49). Bogotá: Universidad Externado de Colombia.

Baumol, W. (1971). "The use of standards and prices for protection of the environment", en The Swedish journal of economic, 73 (1), $42-54$.

DIAN (10 de 01 de 2017). Concepto general No 003259. Bogotá, Colombia.

DIAN (22 de 02 de 2008). Oficio No 018286.

García Novoa, C. (2012). El concepto de tributo. Buenos Aires: Marcial Pons.

Gianni, A. D. (1957). Instituciones del Derecho tributario. Madrid: Derecho Financiero.

Gómez G., L. J. (1997). "Las raíces teóricas del conflicto economía/ecología y algunos desarrollos posteriores a walras", en Ensayos de economía (7), 102-121.

González Villa, J. (2004). "Los vertimientos en Colombia y su regulación”, en U. E. Departamento de Derecho de Medio Ambiente, Derecho de aguas (Vol. II, págs. 163-191). Bogotá: Universidad Externado de Colombia.

Guzmán, P. (2012). Tratados ambientales internacionales y negocios. Bogotá: Universidad Externado de Colombia.

Herrera, P. (2000). La introducción del interés ambiental en el ordenamiento tributario. Madrid: Macial Pons.

Lozano, B. (2009). Derecho ambiental administrativo. Madrid , España: Dykinson, SL.

Martín, M. (1977). Derecho ambiental. Madrid: Instituto de estudios de administración local.

Martín, M. R. (1977). Derecho ambiental. Madrid: Instituto de estudios de administración local.

Martínez, J. (2008). Instrumentos económicos para la protección del medioambiente. Madrid: Dykinson, SL.

Muñoz, A. (2014). Fiscalidad y medioambiente: estado de la cuestión.

Pigou, A. (1932). The Economics of Welfare.

Rudas, G. (3 de agosto de 2016). Conservar el medioambiente, la próxima locomotora de Colombia (M. M. Monsalve, ed.) El Espectador.

Sánchez, C. (2016). "Las tasas ambientales en el sector minero en Colombia", en J. C. Henao, Minería y desarrollo. Medio ambiente y desarrollo sostenible en la actividad minera (Vol. 2, pág. 733). Bogotá: Universidad Externado de Colombia.

Sánchez, C. (2014). "Los impuestos tributarios ambientales, una opción desperdiciada en Colombia”, en D. d. Ambiente, Servicios públicos y medioambiente (Vol.III, págs. 137-174). Bogotá: Universidad Externado de Colombia.

Sánchez, C. (2017). "Impuestos ambientales en la reforma tributaria 2016", en J. Piza, Análisis crítico de la reforma tributaria. Ley 1819 de 2016 (pp. 505-519). Bogotá: Universidad Externado de Colombia.

Sáinz de Bujanda, F. (1976). Notas de Derecho financiero (Vol. 2). Madrid: Universidad de Madrid-Facultad de Derecho.

Tietenberg, T. (1990). "Economic Instruments for Environmental Regulation”, en Oxford Review of Economic Policy, 6 (1), 17-33.

Villegas, H. B. (2009). Curso de finanzas, Derecho financiero y tributario. Buenos Aires: Astrea. 